\title{
Broadband Vibration Attenuation Using Hybrid Periodic Rods
}

\author{
S. Asiri \\ Department of Mechanical Engineering, King Abdulaziz University, P.O. Box 80204, Jeddah 21589, Saudi Arabia
}

Received 13 May 2006; accepted 17 December 2006

تخفيف الاهتزازات على نطاق عريض باستعهال قضبان الهبين الدورية

س. عسيري

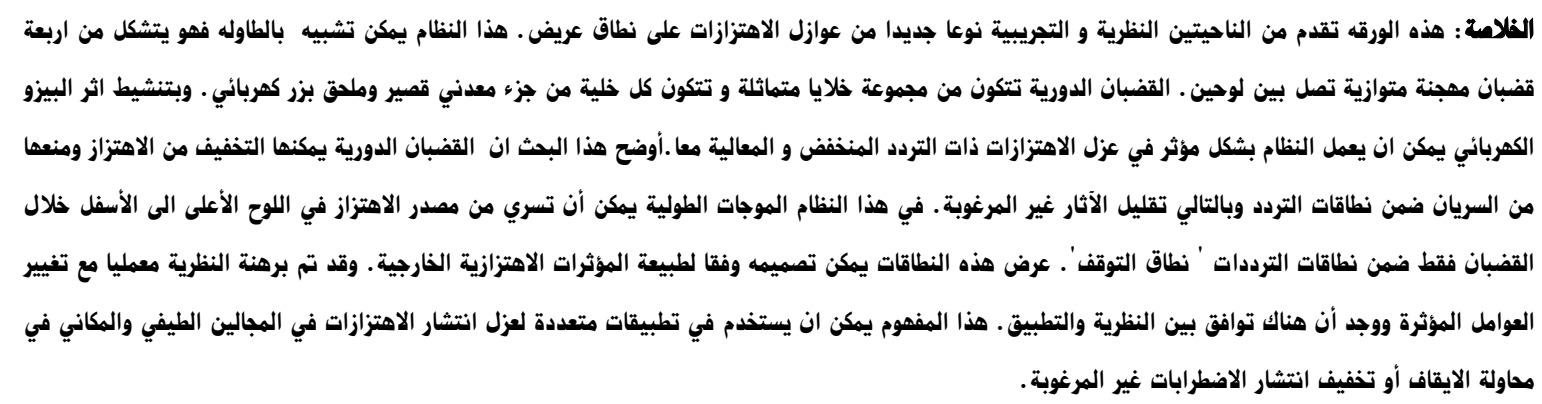

الهزدات الهنتاهية : نطاق المرور ، نطاق التوقف، عازل الاهتزاز عريض الهدى، البيزو كهربائية، خفض الاهتزازات، سريان الموجات، الترشيح القابل للمعايرة.

\begin{abstract}
This paper presents both theoretically and experimentally a new kind of a broadband vibration isolator. It is a table-like system formed by four parallel hybrid periodic rods connected between two plates. The rods consist of an assembly of periodic cells, each cell being composed of a short rod and piezoelectric inserts. By actively controlling the piezoelectric elements, it is shown that the periodic rods can efficiently attenuate the propagation of vibration from the upper plate to the lower one within critical frequency bands and consequently minimize the effects of transmission of undesirable vibration and sound radiation. In such a system, longitudinal waves can propagate from the vibration source in the upper plate to the lower one along the rods only within specific frequency bands called the "Pass Bands" and wave propagation is efficiently attenuated within other frequency bands called the "Stop Bands". The spectral width of these bands can be tuned according to the nature of the external excitation. The theory governing the operation of this class of vibration isolator is presented and their tunable filtering characteristics are demonstrated experimentally as functions of their design parameters. This concept can be employed in many applications to control the wave propagation and the force transmission of longitudinal vibrations both in the spectral and spatial domains in an attempt to stop/attenuate the propagation of undesirable disturbances.
\end{abstract}

Keywords: Pass Band, Stop band, Broadband vibration isolator, Piezoelectricity, Vibration attenuation, Wave propagation, Tunable filtering

\section{Notation}

$\begin{array}{ll}A & \text { Cross-section area } \\ b & \text { Width of piezo-insert } \\ C^{D} & \text { Elastic modulus } \\ D_{p} & \text { Electrical displacement of the piezo-insert } \\ E & \text { Young's modulus } \\ E_{p} & \text { Electrical field intensity of the piezo-insert } \\ F & \text { Force } \\ F_{I} & \text { Total interface force } \\ f_{N} & \text { Excitation harmonic force at the end of strut } \\ F_{p} & \text { piezo-force } \\ h_{p} & \text { Piezo-coupling constant }\end{array}$


The Journal of Engineering Research Vol. 5, No.1 (2008) 7-19

$k_{p c} \quad$ Active piezo-stiffness due to the control gain $K$

$k_{p s} \quad$ Structural piezo-stiffness

$K_{d} \quad$ Dynamic stiffness matrix

$K_{g} \quad$ Control gain

$K_{i j} \quad$ Appropriately partitioned matrices of the stiffness

$K_{p} \quad$ Total stiffness of the piezo-insert

$L \quad$ Element length

$L_{a} \quad$ Length of cell a

$L_{b} \quad$ Length of cell b

$M_{i j} \quad$ Appropriately partitioned matrices of the mass

$N \quad$ Number of cells

$Q_{p} \quad$ Electrical charge

$S_{p} \quad$ Strain of the piezo-insert

$t_{p} \quad$ Thickness of piezo-insert

$T \quad$ Transfer matrix of the unit cell

$T_{k} \quad$ Transfer matrix of the $k^{\text {th }}$ cell

$T_{p} \quad$ Stress of the piezo-insert

u $\quad$ Longitudinal deflection

$V \quad$ Applied voltage

$Y \quad$ State vector $=\left\{\begin{array}{ll}u_{L} & F_{L}\end{array}\right\}^{\mathrm{T}}$

$Y_{k} \quad$ Eigenvetor of transfer matrix of the unit cell

$Y_{k} \quad$ Eigenvetor of the transpose of transfer matrix of the unit cell

$\alpha \quad$ Logarithmic decay of amplitude of state vector

$\beta \quad$ Phase difference between the adjacent cells

$\varepsilon^{\mathrm{s}} \quad$ Electrical permittivity

$\lambda \quad$ Eigenvalue of transfer matrix of the unit cell

$\rho \quad$ Density

$\mu \quad$ Propagation Constant

$\omega \quad$ Excitation frequency

\section{Introduction}

The periodic rods in the proposed mechanical filter act as the transmission paths of the vibration from the upper plate where the source of vibrations is located to the lower plate. Therefore, a proper design of these rods is essential to the attenuation of the vibratory energy and the noise radiated into any structure connected to the lower plate.

A periodic rod consists of an assembly of identical cells connected in a repeating array which together form a 1-D periodic structure. The study of periodic structures has a long history. Wave propagation in periodic systems related to crystals and optics has been investigated for approximately 300 years. Brillouin (1953) developed the theory of periodic structures for solid state applications and then, in the early seventies, the theory was extended to the design of mechanical structures (Mead, 1970; Cremer, et al. 1973). Since then, the theory has been extensively applied to a wide variety of structures such as spring-mass systems Faulkne and Hong, 1985, periodic beams (Mead, 1970; Faulkner and Hong, 1985; Mead, 1971; Mead, 1971; Mead and Markus, 1983; Roy, 1986; Gupta, 1970; Mead, 1986; Richards and Pines, 2003; Mead, 1996), stiffened plates (Gupta, 1970; Mead, 1986; Mead and Yaman, 1991), ribbed shells (Mead, 1987) and space structures. Examples of such structures are found in many engineering applications. These include bulkheads, helicopter drive shafts (Richads and Pines, 2003), airplane fuselages, vehicle engine mounting systems (Asiri, 2005), and helicopter gearbox supporting systems (Asiri, et al. 2002). Each such structure has a repeating set of stiffeners which are placed at regular intervals. Sackman, et al. Sackman, et al. (1999) presented a layered notch filter device that is limited only to high-frequency vibrations. Such a filter which was developed theoretically based on the Floquet theory is a periodically layered stack of two alternating materials with widely different densities and stiffnesses.

The work presented here is an experimental implementation of the work of Baz (2001) in which an active periodic spring mass system is employed theoretically, in a quasi-static manner, to control the wave propagation of longitudinal vibration. Periodic rods in passive mode of operation exhibit unique dynamic characteristics that make them act as mechanical filters for wave propagation. As a result, waves can propagate along the periodic rods only within specific frequency bands called the "Pass Bands" and wave propagation is attenuated within other frequency bands called the "Stop Bands". The spectral width and location of these bands are fixed for a 1-D passive periodic structure, but are tunable in response to the structural vibration for active periodic structures (Baz, 
2001; Asiri, et al. 2004). The shape memory alloy has been used as a source of irregularities to attenuate the wave propagation in periodic rods (Asiri, et al. 2004).

The spectral finite element analysis and transfer matrix method (Baz, 2001; Asiri, et al. 2004; Ruzzene and Baz, 2000; Baz, 2000) will be used to analyze the hybrid periodic rod and determine the propagation parameter, which indicates the regions of stop bands and pass bands.

This paper is organized in four sections. In Section 1, a brief introduction is given. Section 2 presents the theoretical background of the hybrid periodic rod and Section 3 demonstrates the performance characteristics of the tunable mechanical filter. Comparisons between the theoretical and experimental characteristics are also presented in Section 3. Section 4 summarizes the findings and the conclusions of the present study and also outlines the direction for future research.

\section{System Modeling}

\subsection{Overview}

In this section, the emphasis is placed on studying the dynamics of the tunable mechanical filter in order to demonstrate its unique filtering capabilities. The dynamics of one-dimensional hybrid periodic rods in their active and passive modes of operation are determined using the transfer matrix method. The basic characteristics of the transfer matrices of periodic rods are presented and related to the physics of wave propagation along these rods. The methodologies for determining the pass and stop bands as well as the propagation parameters are presented.

In this paper, the focus is placed on hybrid periodic rods consisting of a straight rod with periodically placed piezoelectric inserts as shown in Fig. 1.

Piezoelectric inserts

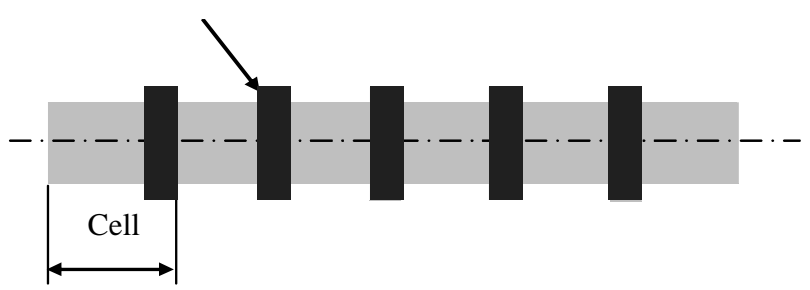

Figure 1. Typical example of hybrid periodic rod

\subsection{Spectral Finite Element Method of the Rod}

The first development of the spectral Finite Element (SFE) method occurred in the early eighties (Patera, 1984). The main distinct between the SFE and Finite Element (FE) stems from the type of the shape functions used to approximate the model equations. In FE method, the shape function is only a function of a spatial variable, whereas in SFE the shape function has two independent variables: the spatial variable $(x)$ and the spectral variable $(\omega)$. As a result, the SFE method is much more accurate than FE method. For example, one can show that the exact natural frequencies for a rod can be found by one element using SFE method, whereas a large number of elements needs to be used to get the same accuracy using the FE method. Consider the rod shown in Fig. 2

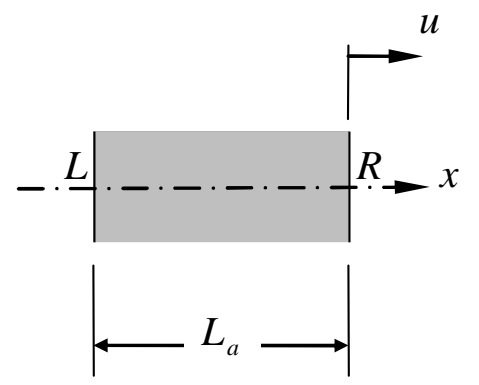

Figure 2. Rod undergoing longitudinal vibrations

The equation of motion of the rod is given by:

$$
u_{x x}-(\rho / E) u_{t t}=0
$$

where $u$ is the longitudinal deflection, $\rho$ is the density and $E$ is Young's modulus.

Then, assuming a solution $u(x, t)=U(x) e^{i \omega t}$, reduces the equation of motion to:

$$
U_{x x}(x)+k^{2} U(x)=0
$$

where $k=$ wave number $=\sqrt{\rho / E} \omega$.

Using the following spectral shape function: $U(x)=$ $A e^{-i k x}+B e^{i k s}$, which is also a solution of Eq. (1), yields the spectral finite element description of the dynamics of the rod. This results in the following dynamic stiffness matrix of the rod:

$[K]=\frac{E A}{L_{a}}\left[\begin{array}{l}\left(1-e^{-4 i k L_{a}}\right) i k L_{a}-2 e^{-3 i k L_{a}}\left(-1+e^{2 i k L_{a}}\right) i k L_{a} \\ -2 e^{-3 i k L_{a}}\left(-1+e^{2 i k L_{a}}\right) i k L_{a} \quad\left(1-e^{\left.-4 i k L_{a}\right) i k L_{a}}\right.\end{array}\right.$

The corresponding Transfer Matrix [T] takes the following form:

$$
[T]=\left[\begin{array}{lc}
-K_{d_{L R}}^{-1} K_{d_{L L}} & K_{d_{L R}}^{-1} \\
K_{d_{R R} K_{d_{L R}}^{-1} K_{d_{L L}}-K_{d_{R L}}}-K_{d_{R R} K_{d_{L R}}^{-1}}
\end{array}\right]
$$

where

$$
\begin{gathered}
K_{d_{L L}}=\frac{E A}{L}\left(1-e^{-4 i k L}\right) i k L, K_{d_{L R}}=\frac{E A}{L}\left(-2 e^{-3 i k L}\left(-1+e^{2 i k L}\right) i k L\right) \\
K_{d_{R L}}=\frac{E A}{L}\left(-2 e^{-3 i k L}\left(-1+e^{2 i k L}\right) i k L\right), \text { and } \\
K_{d_{R R}}=\frac{E A}{L}\left(1-e^{-4 i k L}\right) i k L .
\end{gathered}
$$

\subsection{Dynamics of the Hybrid Rod}

Consider now the dynamics of the hybrid periodic rods which consists of a passive sub-cell and an active piezoelectric sub-cell as shown in Fig. 3. 


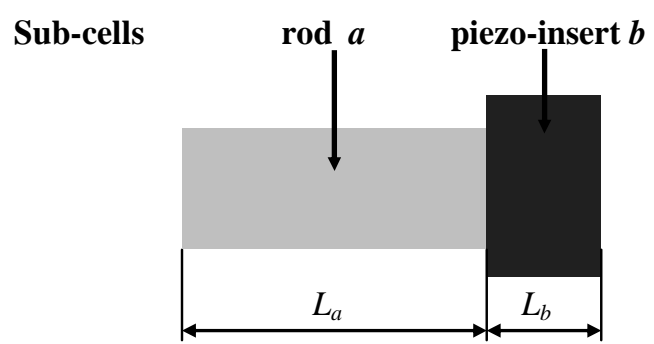

(a) Complete cell

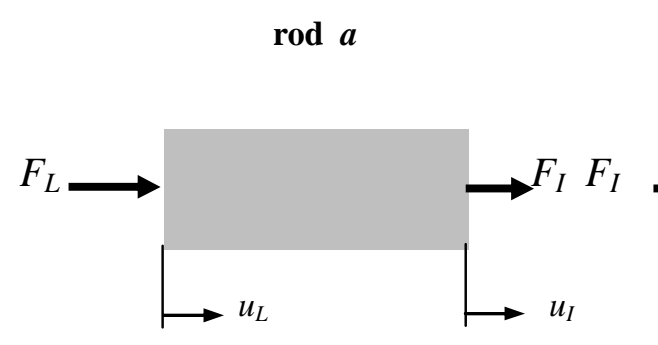

Piezo-insert $b$

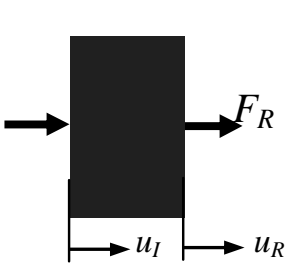

Interface (I)

Right (R)
(b) passive sub-cell
(c) - active sub-cell

\section{Figure 3. Unit cell of the hybrid periodic rod}

\subsubsection{Passive Sub-cell}

As shown in Eq. (4), the dynamic characteristics of the passive sub-cell (a) can be described as follows:

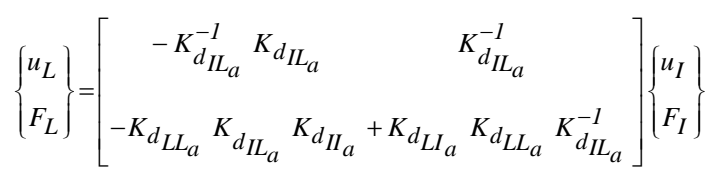

where $u$ and $F$ define the deflection and force vectors with subscripts $L$ and $I$ denoting the left and interface sides of the passive sub-cell and $K_{d_{i j a}}$ defines the elements of dynamic stiffness matrix of the sub -cells $\boldsymbol{a}$ which can be calculated from Eq. (5).

In a more compact form, Eq. (6) can be rewritten as:

$$
\left\{\begin{array}{c}
u_{L} \\
F_{L}
\end{array}\right\}=T_{a}\left\{\begin{array}{c}
u_{I} \\
F_{I}
\end{array}\right\}
$$

where is the transfer matrix of the passive sub-cell a. One can show that the transfer matrix is a simplectic matrix (Asiri, et al. 2002).

\subsubsection{Active Sub-cell}

The constitutive equations of the active piezoelectric insert are given by Baz (2001):

$$
\left\{\begin{array}{l}
E_{p} \\
T_{p}
\end{array}\right\}=\left[\begin{array}{cc}
1 / \varepsilon^{S} & -h_{p} \\
-h_{p} & C^{D}
\end{array}\right]\left\{\begin{array}{l}
D_{p} \\
S_{p}
\end{array}\right\}
$$

where $E_{p}, D_{p}, T_{p}$ and $S_{p}$ are the electrical field intensity, electrical displacement, stress and strain of the piezoinsert. Moreover, $\varepsilon^{S}, h_{p}$ and $C^{D}$ define the electrical permittivity, piezo-coupling constant and elastic modulus.

Eq. (8) can be rewritten in terms of applied voltage $V_{p}$, Interface piezo-force $F_{I}$, electrical charge $Q_{p}$ and net deflection $\left(u_{R}-u_{I}\right)$ as follows:

$$
\left\{\begin{array}{l}
V_{p} / t_{p} \\
F_{I} /\left(\pi D_{b}^{2} / 4\right)
\end{array}\right\}=\left[\begin{array}{cc}
1 / \varepsilon^{S} & -h_{p} \\
-h_{p} & C^{D}
\end{array}\right]\left\{\begin{array}{l}
Q_{p} / D_{b} L_{b} \\
\left(u_{R}-u_{I}\right) / L_{b}
\end{array}\right\}
$$

where $t_{p}$ and $b$ are the diameter and the length of the piezo insert.

Eliminating the charge Qp from Eq. (9) gives:

$$
F_{I}=-h_{p} \varepsilon^{S} D_{b} V_{p}+\left[\left(\pi D_{b}^{2} / 4\right)\left(C^{D}-h_{p}^{2} \varepsilon^{S}\right) / L_{b}\right]\left(u_{R}-u_{I}\right)
$$

Let the piezo-voltage $V_{p}$ be generated according to the following control law:

$$
V_{p}=-K_{g}\left(u_{R}-u_{I}\right)
$$

where $K_{g}$ is the control gain which can be complex if phase shift is allowed. Appropriate phase shift means that the piezo-insert can act as a damper.

Then, Eq (10) reduces to:

$$
\begin{aligned}
F_{I} & =\left\{h_{p} \varepsilon^{S} b K_{g}+\left[\left(t_{b} b\left(C^{D}-h_{p}^{2} \varepsilon^{S}\right) / L_{p}\right]\right\}\left(u_{R}-u_{I}\right)\right. \\
& =\left(k_{p c}+k_{p s}\right)\left\{\begin{array}{ll}
-1 & 1
\end{array}\right\}\left\{\begin{array}{l}
u_{I} \\
u_{R}
\end{array}\right\}
\end{aligned}
$$

where $k_{p c}=h_{p} \varepsilon^{S} D_{b} K_{g}$ and $k_{p s}=\left[\left(\pi D_{b}^{2} / 4\right)\left(C^{D}-h_{p}^{2} \varepsilon^{S}\right) / L_{b}\right]$ with $k_{p c}$ and $k_{p s}$ denoting the active piezo -stiffness due to the control gain $K_{g}$ and the structural piezo -stiffness, respectively.

Eq. (12) can be used to generate the force vector $\left\{F_{1} F_{R}\right\}^{T}$ acting on the piezo-insert rewritten as:

$$
\left\{\begin{array}{l}
F_{I} \\
F_{R}
\end{array}\right\}=\left(k_{p c}+k_{p s}\right)\left\{\begin{array}{l}
-1 \\
1
\end{array}\right\}\{-11\}\left\{\begin{array}{l}
u_{I} \\
u_{R}
\end{array}\right\}=\left[\begin{array}{cc}
k_{p} & -k_{p} \\
-k_{p} & k_{p}
\end{array}\right]\left\{\begin{array}{l}
u_{I} \\
u_{R}
\end{array}\right\}
$$

with $k_{p}=k_{p c}+k_{p s}$ is the total stiffness of the piezo-insert which is complex if the gain is complex by virtue of the phase shift.

Hence, the dynamic equation of the active sub-cell is given by:

$\left[\begin{array}{ll}K_{d_{I I_{b}}} & K_{d_{I R_{b}}} \\ K_{d_{R I_{b}}} & K_{d_{R R_{b}}}\end{array}\right]\left\{\begin{array}{l}u_{I} \\ u_{R}\end{array}\right\}=\left\{\begin{array}{l}F_{I} \\ F_{R}\end{array}\right\}$ 
where $K_{d_{i j b}}$ defines the elements of dynamic stiffness matrix of the sub-cell $\boldsymbol{b}$ which can be calculated from Eq. (13).

Now, the state vectors at ends $R$ and $I$ of the passive sub-cell $\boldsymbol{b}$ are related through the transfer matrix derived from Eq. (14) as follows:

$$
\left\{\begin{array}{c}
u_{R} \\
F_{R}
\end{array}\right\}=\left[\begin{array}{ccc}
-K_{d_{I R_{b}}}^{-1} K_{d_{I I_{b}}} & K_{d_{I R_{b}}}^{-1} \\
-K_{d_{R R_{b}}} K_{d_{I R_{b}}}^{-1} & K_{d_{I I_{b}}}+K_{d_{R R_{b}}} K_{d_{I R_{b}}}^{-1}
\end{array}\right]\left\{\begin{array}{c}
u_{I} \\
F_{I}
\end{array}\right\}
$$

In a more compact form, Eq. (15) can be rewritten as:

$$
\left\{\begin{array}{l}
u_{R} \\
F_{R}
\end{array}\right\}=T_{b}\left\{\begin{array}{l}
u_{I} \\
F_{I}
\end{array}\right\} \text { where } T_{b} \text { is the transfer matrix of the }
$$
active sub-cell $\boldsymbol{b}$.

\subsubsection{Dynamics of Entire Cell}

The dynamics of the entire cell can be determined by the assembly of the dynamic equations of the passive and active sub-cells which are given by Eq. (3) and Eq. (15) respectively. This yields the following dynamic equations:

$$
\left\{\begin{array}{l}
u_{L} \\
F_{L}
\end{array}\right\}_{k+1}=\left[T_{k}\right]\left\{\begin{array}{l}
u_{L} \\
F_{L}
\end{array}\right\}_{k}
$$

where $T_{k}=T_{b} \cdot T_{a}=\left[\begin{array}{ll}t_{11} & t_{12} \\ t_{21} & t_{22}\end{array}\right]$

In a more compact form, Eq. (16) can be rewritten as:

$$
Y_{k+1}=\left[T_{k}\right] Y_{k}
$$

where $Y$ and $\left[T_{k}\right]$ denote the state vector $=\left\{\begin{array}{ll}u_{L} & F_{L}\end{array}\right\}^{T}$ and the transfer matrix of the $k$ cells.

For exactly periodic rods, $\left[T_{k}\right]=[T]$ and the eigenvalue problem of $[T]$ can be written as:

$$
[T] y_{k}=\lambda Y_{k}
$$

where $\lambda$ is the eigenvalue of $[T]$

Combining Eq. (17) and (18) gives:

$$
Y_{k+1}=\lambda Y_{k}
$$

Indicating that $\lambda$ of the matrix $[T]$ is the ratio between the elements of the state vectors at two consecutive cells. Hence, the magnitude of $\lambda$ determine the nature of wave dynamics in the periodic rod as follows:

If $|\lambda|=1$, the wave propagates along the rod without any change of amplitude, indicating a Pass Band and if not then the wave will be attenuated, indicating a Stop Band.
A further explanation of the physical meaning of the eigenvalue $\lambda$ can be extracted by rewriting it as:

$$
\lambda=e^{\mu}=e^{\alpha+i \beta}
$$

where $\mu$ is defined as the "Propagation Factor" which is a complex number whose real part $(\alpha)$ represents the logarithmic decay of the state vector and its imaginary part $(\beta)$ defines the phase difference between the adjacent cells.

One can rewrite Eq. (19) as:

$$
\left\{\begin{array}{l}
u_{L} \\
F_{L}
\end{array}\right\}_{k+1}=e^{\alpha+i \beta}\left\{\begin{array}{l}
u_{L} \\
F_{L}
\end{array}\right\}_{k}
$$

and considering only the $j^{\text {th }}$ components $u_{L_{j}}$ of the deflection vector $u_{L}$, at cells $k$ and $k+1$, which can be written as:

$$
u_{L_{j k+1}}=U_{L_{j k+1}} \text { and } u_{L_{j k}}=e^{i \phi_{j k}}
$$

where $U_{L_{j n}}$ and $\phi_{j n}$ denote the amplitude and phase shift of the $j^{\text {th }}$ component $u_{L_{j}}$ at the $n^{\text {th }}$ cell.

From Eq. (21) and Eq.(22), we get:

$$
\begin{aligned}
& \ln \left(u_{L_{j k+1}} / u_{L_{j k}}\right)=\ln \left(U_{L_{j k+1}} / U_{L_{j k}}\right) \\
& \quad+i\left(\phi_{j k+1}=\phi_{j k}\right)=\alpha+i \beta
\end{aligned}
$$

Eq. (19) indicates that:

$$
\begin{aligned}
\alpha=\ln \left(U_{L_{j_{k+1}}} / U_{L_{j_{k}}}\right)= & \text { Logarithmic decay of } \\
& \text { amplitude, }
\end{aligned}
$$

and $\beta=\left(\phi_{j k+1}-\phi_{j k}\right)=$ phase difference between the adjacent cells

Therefore, the equivalent conditions for the Pass and the Stop bands can be written in terms of the propagation constant parameters ( $\alpha$ and $\beta$ ) as follows:

a. If $\alpha=0$ (ie. $\mu$ is imaginary), then we have "Pass Band" as there is no amplitude attenuation.

b. If $\alpha \neq 0$ (ie. $\mu$ is real or complex), then we have

"Stop Band" " as there is amplitude attenuation defined by the value of $\alpha$.

The propagation factor, $\mu$, can be calculated directly from the diagonal elements of overall transfer matrix as following:

$$
\mu=\operatorname{acosh}\left(\frac{t_{11}+t_{22}}{2}\right)
$$

In case of a rod element, the transfer function has two eigenvalues $\mu$ and $1 / \mu$ and according to the properties of 
the simplectic matrix (or transfer matrix), the trace is equal to the summation of the eigenvalues. So one can show that:

$\mu=\operatorname{acosh}\left(\frac{\lambda+1 / \lambda}{2}\right)$

A better insight into the physical meaning of the eigenvalues $\mu$ and $\mu^{-1}$ can be gained by considering the following transformation of the cell dynamics into the wave mode component domain:

$$
\begin{aligned}
& Y_{k}=\left\{\begin{array}{c}
u_{L} \\
\left.F_{L}\right\}_{k}=\Phi W_{k}=\Phi\left\{w_{L}^{r}\right\}_{k} \\
\text { and } Y_{k+1}=\left\{\begin{array}{c}
u_{L} \\
F_{L}
\end{array}\right\}_{k+1}=\Phi W_{k+1}=\Phi\left\{\begin{array}{c}
w_{L}^{r} \\
w_{L}^{L}
\end{array}\right\}_{k+1}
\end{array}\right.
\end{aligned}
$$

where $\Phi$ is the eigenvector matrix of the transfer matrix [T]. Also, $\mathrm{W}_{\mathrm{k}}$ is the wave mode component vector which has the right -going wave component $\mathrm{w}^{\mathrm{r}}$ and left-going wave component $\mathrm{w}^{\mathrm{L}}$.

Substituting Eq. (26) into Eq. (25), it reduces to:

$$
\begin{aligned}
& Y_{k+1}=\Phi\left\{\begin{array}{c}
w_{L}^{r} \\
w_{L}^{L}
\end{array}\right\}_{k+1}=[T] Y_{k}=(T) \Phi\left\{\begin{array}{c}
w_{L}^{r} \\
w_{L}^{L}
\end{array}\right\}_{k}, \\
& \text { or }\left\{\begin{array}{c}
w_{L}^{r} \\
w_{L}^{L}
\end{array}\right\}_{k+1}+\Phi^{-1}[T] \Phi\left\{\begin{array}{c}
w_{L}^{r} \\
w_{L}^{L}
\end{array}\right\}_{k}
\end{aligned}
$$

Note that the matrix $\Phi^{-1}(\mathrm{~T}) \Phi$ reduces to the matrix of eigenvalues of the matrix $[T], i e .:$

$$
\left\{\begin{array}{c}
w_{L}^{r} \\
w_{L}^{L}
\end{array}\right\}_{k+1}=\operatorname{drag}\left(\lambda_{1}, \lambda_{2}, \ldots, \lambda_{2 n-1}, \lambda_{2 n}\right)\left\{\begin{array}{c}
w_{L}^{r} \\
w_{L}^{L}
\end{array}\right\}_{k}
$$

But, because of the particular nature of the eigenvalues of $[T]$ as they appear in pairs $\left(\mu, \mu^{-1}\right)$, then the above equation reduces to:

$$
\left\{\begin{array}{c}
w_{L}^{r} \\
w_{L}^{L}
\end{array}\right\}_{k+1}=\left[\begin{array}{cc}
\Lambda & 0 \\
0 & \Lambda^{-1}
\end{array}\right]\left\{\begin{array}{c}
w_{L}^{r} \\
w_{L}^{L}
\end{array}\right\}_{k}
$$

where $\Lambda=\operatorname{diag}\left[\lambda_{1}, \lambda_{2}, ..\right]$, and $\Lambda^{-1}=\operatorname{diag}\left[\lambda_{1}^{-1}, \lambda_{2}^{-1}, ..\right]$.

Eq. (29) can be expanded to give:

$$
w_{L_{k+1}}^{r}=\Lambda w_{L_{k}}^{r} \text {, and } w_{L_{k+1}}^{L}=\Lambda^{-1} w_{L_{k}}^{L}
$$

For the $j^{\text {th }}$ component of $w$, we have:
$w_{L_{j_{k+1}}}^{r}=\lambda_{j} w_{L_{j_{k}}}^{r}$, and $w_{L_{j_{k+1}}}^{L}=\lambda_{j}^{-1} w_{L_{j_{k}}}^{L}$

It is clear from Eq. (31) that the eigenv alue $\lambda_{j}$ is the ratio between the amplitude of the right -going waves whereas $\lambda_{j}^{-1}$ defines the ratio between the amplitude of the left-going waves. Hence, if $\left(\lambda_{j}<1\right)$, then $\left(\lambda_{j}^{-1}>1\right)$ and the pair of $\left(\lambda_{j}, \lambda_{j}^{-1}\right)$ and the pair of $\left(\lambda_{j}, \lambda_{j}^{-1}\right)$ denote attenuation of the amplitude of wave propagation from cell $k$ to cell $k+1$. This can be clearly understood by considering Fig. 5 .

Note that the right -going wave ( $w_{L_{j_{k}}}^{r}$ ) is attenuated by $\lambda_{j}$ as it propagates from cell $k$ to $k+1$ and the resulting wave $\left(w_{L_{j_{k+1}}}^{r}\right)$ has a lower amplitude as $w_{L_{j k+1}}^{r}=\lambda_{j} w_{L_{j k}}^{r}$ from the first part of Eq. (31). The left-going wave $\left(w_{L_{j_{k+1}}}^{L}\right)$ is amplified by $\lambda_{j}^{-1}$ as it propagates from cell $k+1$ to cell $k$. Hence, the left going wave $\left(w_{L_{j_{k+1}}}^{L}\right)$, at cell $k+1$, has a lower amplitude than that at $k$. Accordingly, the amplitudes of both the right and left -going waves $\left(w_{L_{j_{k}}}^{r}\right.$ and $w_{L_{j_{k}}}^{L}$ ) at the left end of cell $k$ are higher than the right and left-going waves ( $w_{L_{j_{k+1}}}^{r}$ and $\left.w_{L_{j_{k+1}}}^{L}\right)$ at left end of cell $k+1$.

Therefore, if $\left(\lambda_{j}\right)<1$, then the pair $\left(\lambda_{j}, \lambda_{j}^{-1}\right)$ define attenuation (or stop bands) along the wave propagation direction from cell $k$ to cell $k+1$. Also, if $\left(\lambda_{j}\right)=1$, then the pair ( $\lambda_{j}, \lambda_{j}^{-1}$ ) define propagation without attenuation (ie. pass bands).

\section{System Performance}

\subsection{Overview}

In order to demonstrate the feasibility of the theoretical concepts presented, experimental investigations are conducted. These investigations were carried out on two main steps. In the first step, the vibration attenuation characteristics of the hybrid periodic rod with two actuators on the shaker was studied and evaluated. In the second step, the tunable mechanical filter is used to evaluate its performance for attenuating the vibration transmission from the vibration source, the motor, to the lower plate.

In the present study, the piezo actuators model 712A02 (see the index Table 1) from PCB piezotronics, Inc. (Depew, NY) are used. The actuator shown in Fig. 5 has 


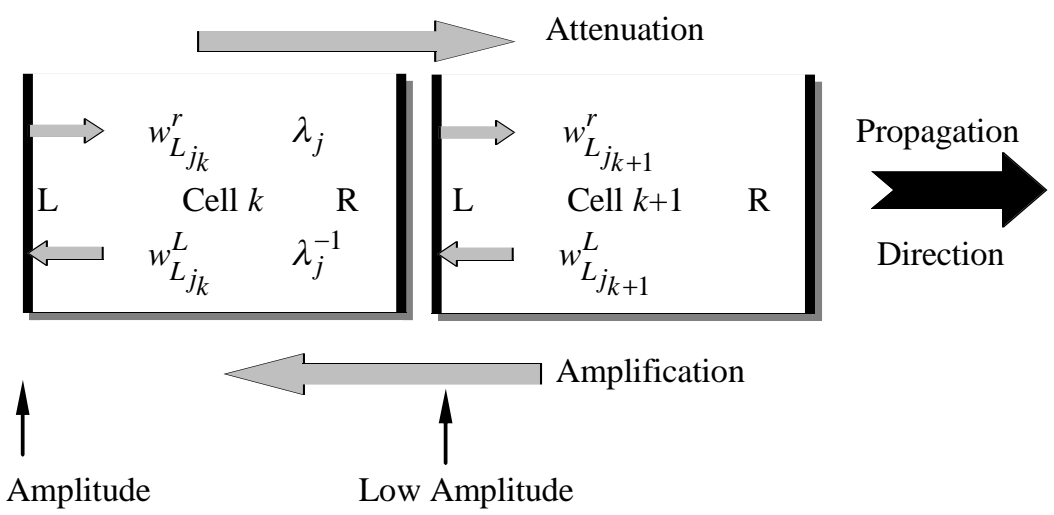

High Amplitude

Low Amplitude

Figure 4. Attenuation of right and left-going waves in the propagation direction

two built-in side bolts so that the short aluminum rods can be bolted from both sides. Figure 6 shows the frequency response characteristics of the actuator authority between 150-5000 Hz with a sensitivity of 0.015 pound/volt and a peak excitation voltage of 100 Volts.

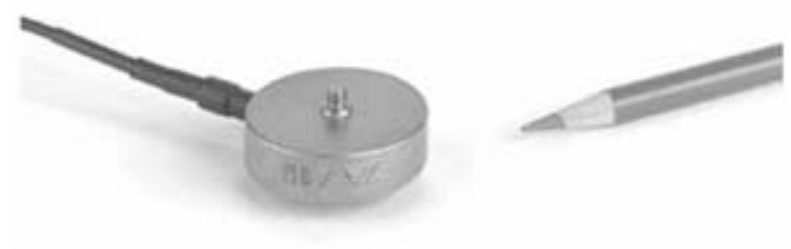

Figure 5. Piezoelectric actuator PCB Piezotronic Model 712A02

\subsection{Experimental Facilities}

Figure (7a) shows the dimensions of the hybrid periodic rod used to build the tunable mechanical filter. It consists of three short aluminum rods shown (see for properties Table 2 in the appendix) bolted together by the actuator as shown in Fig. (7b). The fundamental longitudinal natural frequency of the periodic rod is $640 \mathrm{HZ}$. The frequency response of such a rod is obtained both in its passive (open-loop) and active (closed-loop) modes of operation.

Two experimental test rigs have been employed in this study to evaluate the performance of the tunable mechanical filter. The first test rig aims at monitoring the vibration transmission characteristics of the hybrid rod alone as influenced by geometrical and material discontinuities. Figure 8 shows the details of the employed test facility.

The objective is to measure the transfer function between the input excitation, the shaker, and the output response of the tip of the rod.

First, for the passive plain rod (ie. no periodicity and open circuit), second, for the passive periodic rod (ie. with periodicity and open circuit), and third, for the hybrid periodic rod (ie. with periodicity and short circuit). The phase shifter has been used to introduce a feedback signal to the actuator to produce the destructive interference of waves.

The experimental setup shown in Fig. 9 was used to demonstrate the feasibility of using the tunable mechanical filter to isolate the vibrations induced by a motor. The experiment has been done for the three cases described
Table 1. The main geometrical and performance parameters of the actuators

\begin{tabular}{|c|c|c|c|}
\hline Dynamic & Frequency & & 150 to \\
\hline Performance & Range, Hz & & 5000 \\
\hline & Broadband & & 0.004 \\
\hline & $\begin{array}{l}\text { Force (min), } \\
\text { Ib/volt }\end{array}$ & & \\
\hline Static & Clamped & & 0.015 \\
\hline Performance & Force, Ib/volt & & \\
\hline & Free & & 2.56 \\
\hline & $\begin{array}{l}\text { Displacement, } \\
\text { ì in/volt }\end{array}$ & & \\
\hline Environmental & $\begin{array}{l}\text { Temperature, } \\
{ }^{\circ} \mathrm{F}\end{array}$ & & $\begin{array}{ll}-10 & \text { to } \\
+150\end{array}$ \\
\hline Electrical & $\begin{array}{l}\text { Capacitance } \\
\mathrm{nF}\end{array}$ & & 65 \\
\hline & $\begin{array}{l}\text { Resistance } \\
\text { ohm (min) }\end{array}$ & & $1 \times 10^{7}$ \\
\hline & Input Voltage & & -125 to \\
\hline & (max), Vpk & Excitation & 500 \\
\hline & & $\begin{array}{l}\text { AC } \\
\text { Excitation } \\
\text { (off } \\
\text { resonance) }\end{array}$ & \pm 100 \\
\hline & & & \pm 80 \\
\hline & & $\begin{array}{l}\text { Excitation } \\
\text { (on } \\
\text { resonance) }\end{array}$ & \\
\hline Mechanical & Weight, oz & & 1.27 \\
\hline & Size, in & Height & 0.4 \\
\hline & & Diameter & 2.0 \\
\hline & Electrical & & $\mathrm{BNC}$ \\
\hline & connector & & Plug \\
\hline & Mounting & & $10-32$ \\
\hline & Thread & & Male \\
\hline & Housing & & Titanium \\
\hline & Material & & \\
\hline & Sealing Type & & $\begin{array}{l}\text { Welded } \\
\text { Hermetic }\end{array}$ \\
\hline
\end{tabular}

Table 2. Material properties of the aluminum rods

$\begin{array}{ll}\text { Material } & \text { Aluminum } \\ \text { Density } & 2700 \mathrm{~kg} / \mathrm{m}^{2} \\ \text { Modulus of Elasticity } & 71 \mathrm{GPa} \\ \text { Wave Speed } & 5128 \mathrm{~m} / \mathrm{s}\end{array}$

in first test rig. Two phase shifters have been used to produce the negative feedback signals to the two actuators. 

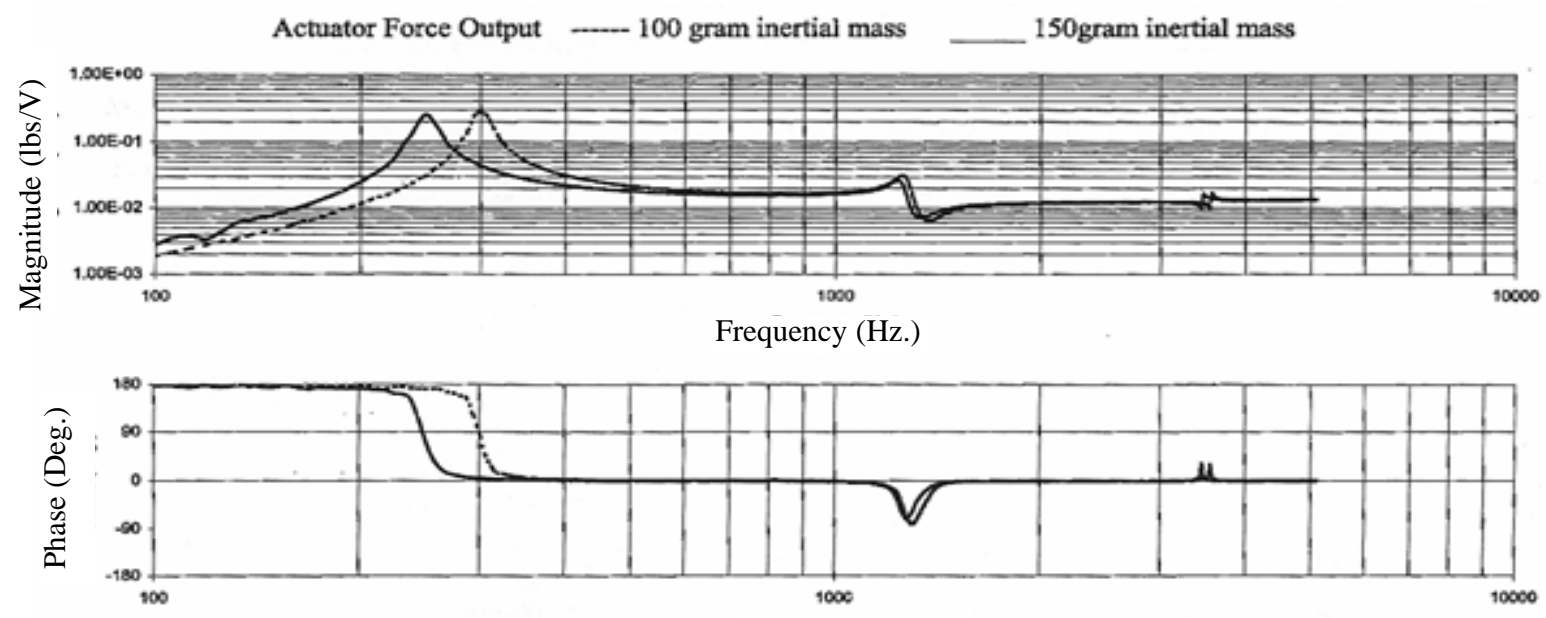

Frequency (Hz.)

Figure 6. The frequency response characteristics of the actuator authority

(a)

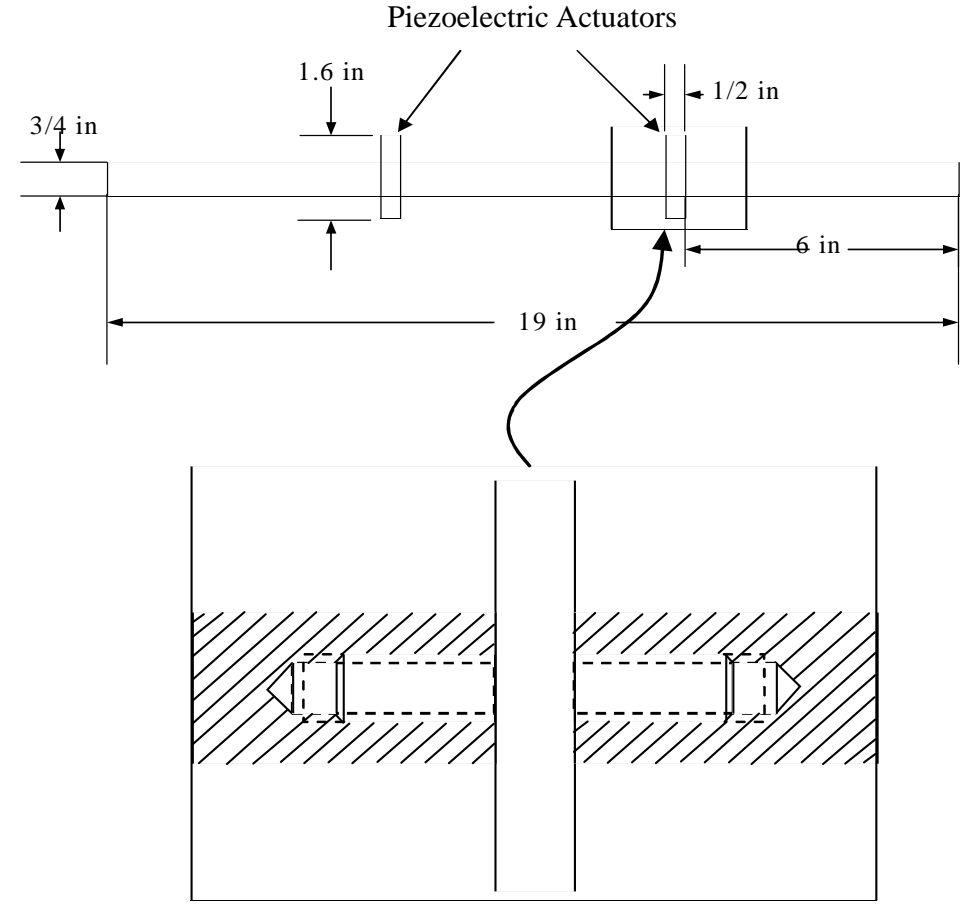

Figure 7. Geometrical parameters of the hybrid rod

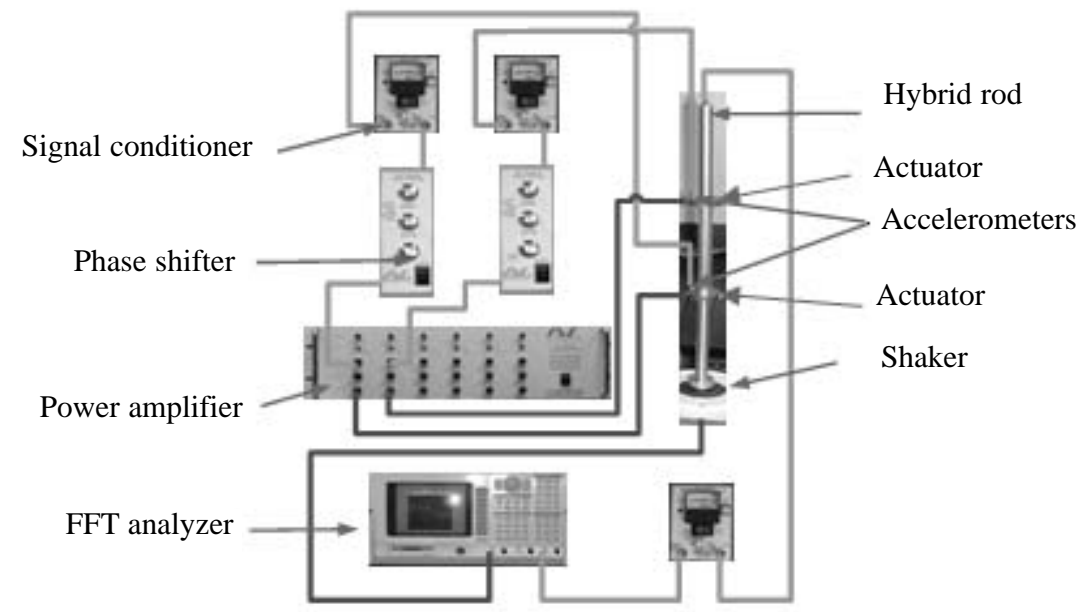

Figure 8. Test setup for evaluating the vibration transmission characteristics of the rod 

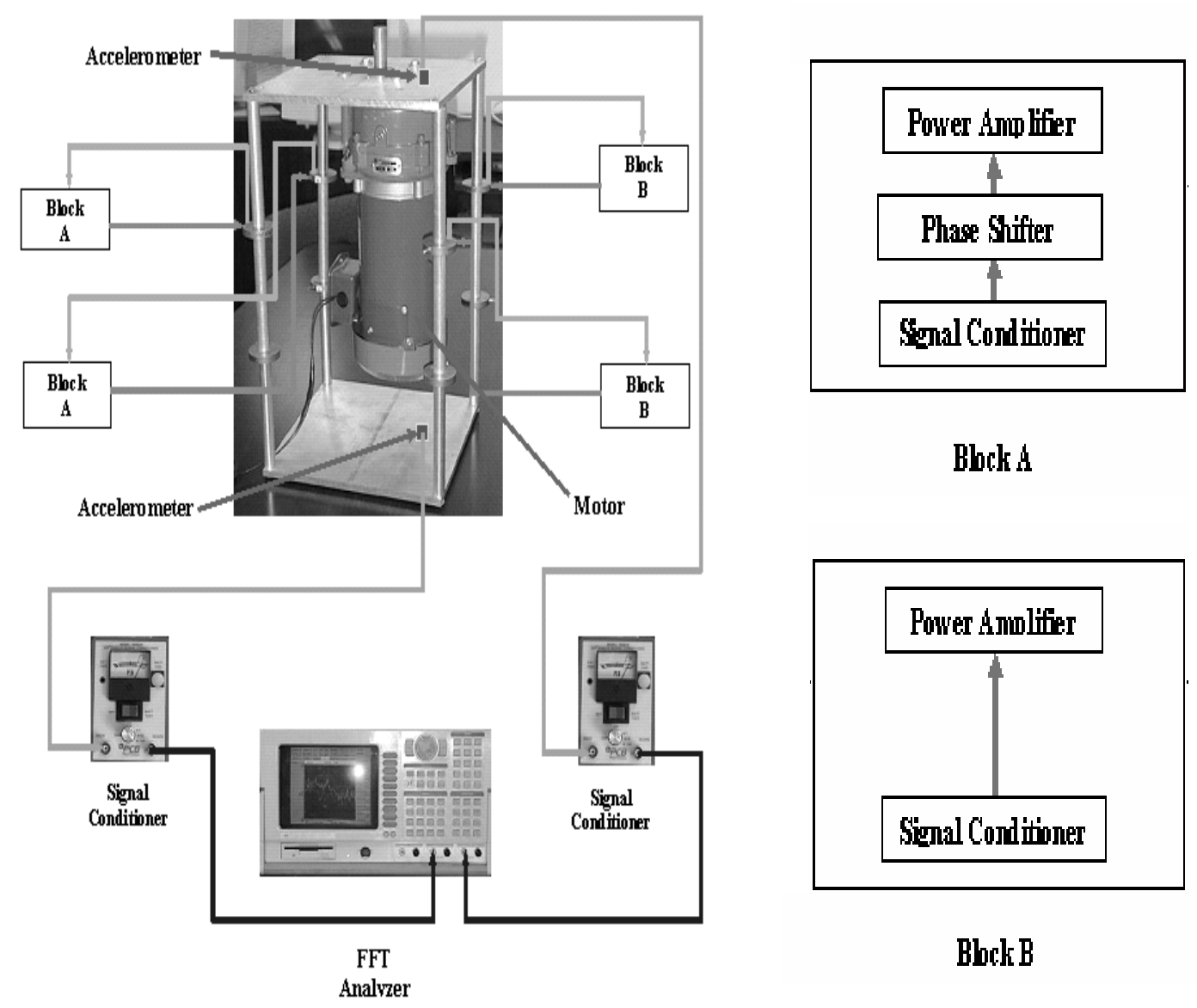

Bbck A

Figure 9. Experimental setup used to demonstrate the feasibility of using the table-like to isolate the vibrations induced by the motor

\subsection{Experimental Results}

\subsubsection{Single Hybrid Rod}

Figure 10a shows the magnitude of the transfer functions of plain, passive periodic, and hybrid periodic rods when they are subjected to random excitation in the axial direction. These transfer functions quantify the response of the free end of the ro ds to input excitations at the other end of the rods. Figure 10a indicates clearly that the passive periodic rod exhibits experimentally a broad stop band between $650-4000 \mathrm{~Hz}$ whereby the vibration transmission through the rod is almo st eliminated. Further more, Fig. 10a indicates that the hybrid rod provides an effective means for attenuating the vibration transmission over a very broad frequency range. It is particularly effective for stopping the low frequency vibration in the range below $600 \mathrm{~Hz}$ where the passive periodic rod has been ineffective. This result is particularly important in using a hybrid rod that combines both the passive and active strategies to stop high as well as low frequency wave propagation. Figure 10b shows that the widths of the st op bands can be clearly predicted theoretically by plotting the real part $\alpha$ of the propagation parameter $\mu$. For values of $\alpha$ $\neq 0$, the stop bands can be cle arly identified and match closely the experimental results for both the passive and hybrid rods.
In all the reported results, the hybrid periodic rod has provided a viable means for extending the width of the stop band between 0-4000 Hz. Also, attenuations of more than $20 \mathrm{~dB}$ are obtained with control voltages less than 5 volts as shown in Fig. 11 for the two control actuators. Note that frequency range higher than $4000 \mathrm{~Hz}$ was not considered because of the limitation imposed by the actuator bandwidth. Figure 12 displays the lateral vibration distribution over plain, passive periodic, and hybrid periodic rods at four different frequencies using the PSV-200 scanning laser vibrometer. Figure 12 shows that the lateral vibration transmission is attenuated also in addition to the longitudinal waves whenever the frequencies lie inside the stop band with the hybrid periodic rod out-performing the plain and the passive periodic rods.

\subsubsection{The Table-like System}

Figure 13 shows the transfer function of the tunable mechanical filter with plain, passive periodic, and hybrid periodic rods when it is subjected to broad band excitations from vibration source, the motor. The excitation from the motor can be considered as a random excitation and the geometrical information of the configuration of rods is the same as shown in Fig. 7. The periodic rods in active mode are very efficient in the low frequency range while in the high frequency range they have the same effi- 
(a)
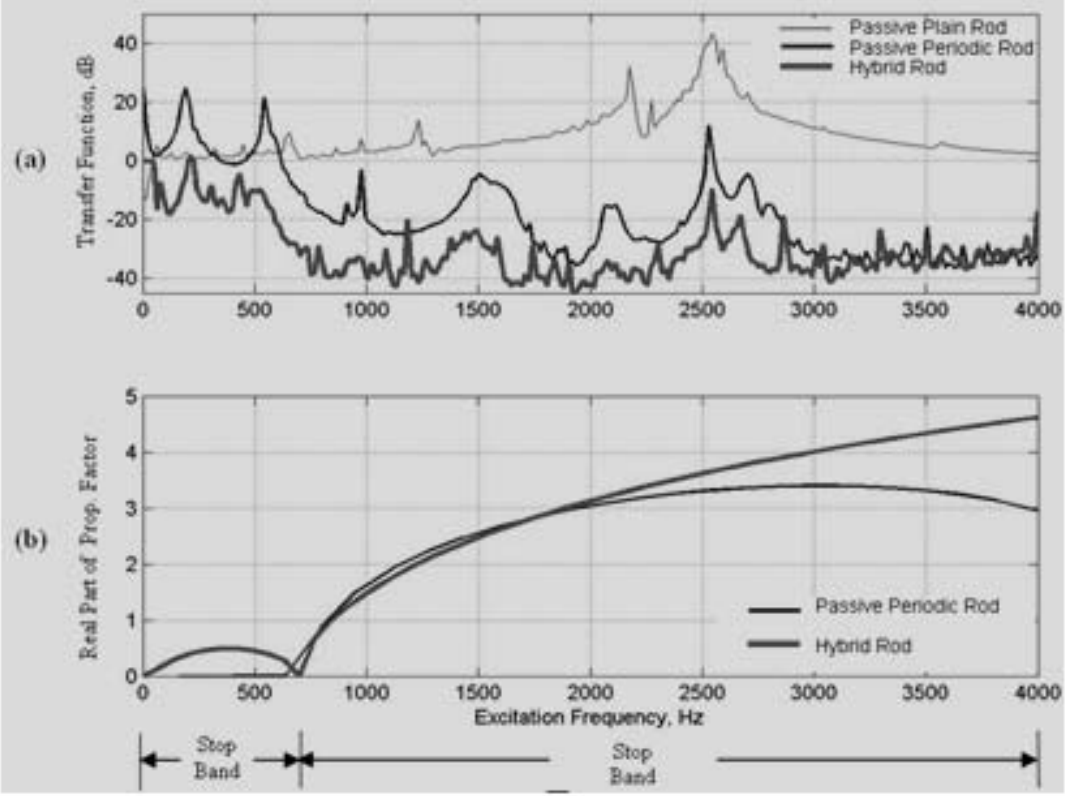

Figure 10. The transfer functions of the plain, passive periodic, and hybrid periodic rods with the propagation factor in both passive and active modes

(a)
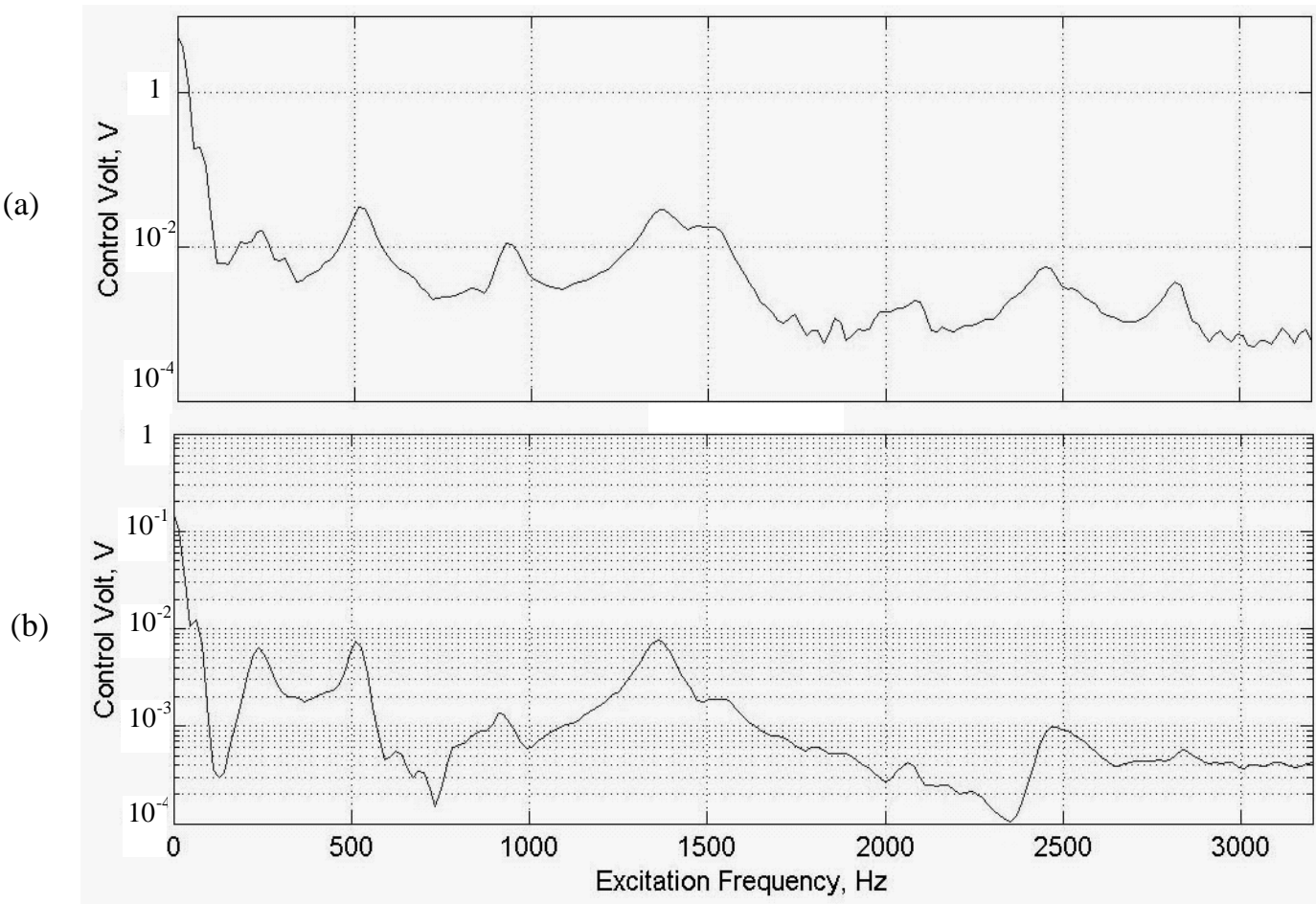

Figure 11. The control voltage of (a) the lower actuator, and (b) the upper actuator

ciency of the passive mode. That is why the blue and green lines in Fig. 13 have the same trend above $1500 \mathrm{~Hz}$. The corresponding control voltage of the upper control actuators is shown in Fig. 14.

\section{Conclusions}

This paper has presented the tunable mechanical filter as a new tool for isolating vibrations. It consists of four 
The Journal of Engineering Research Vol. 5, No.1 (2008) 7-19
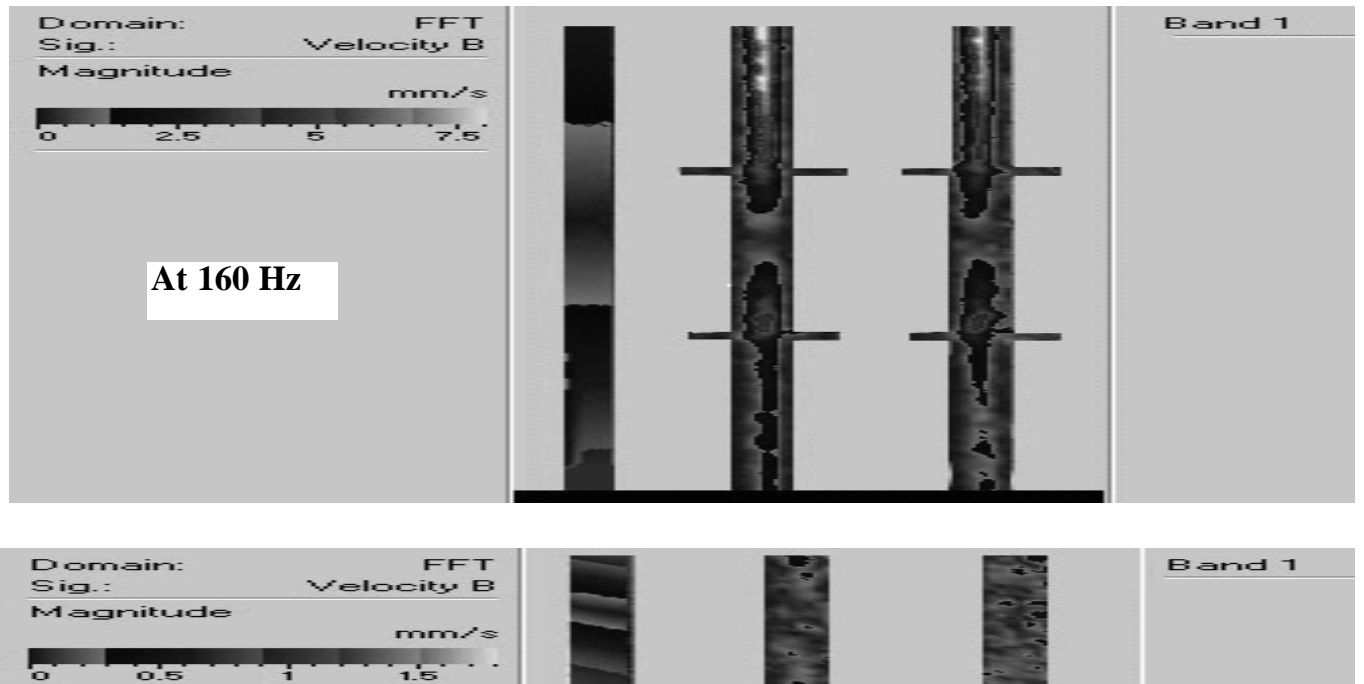

(b)

(a)
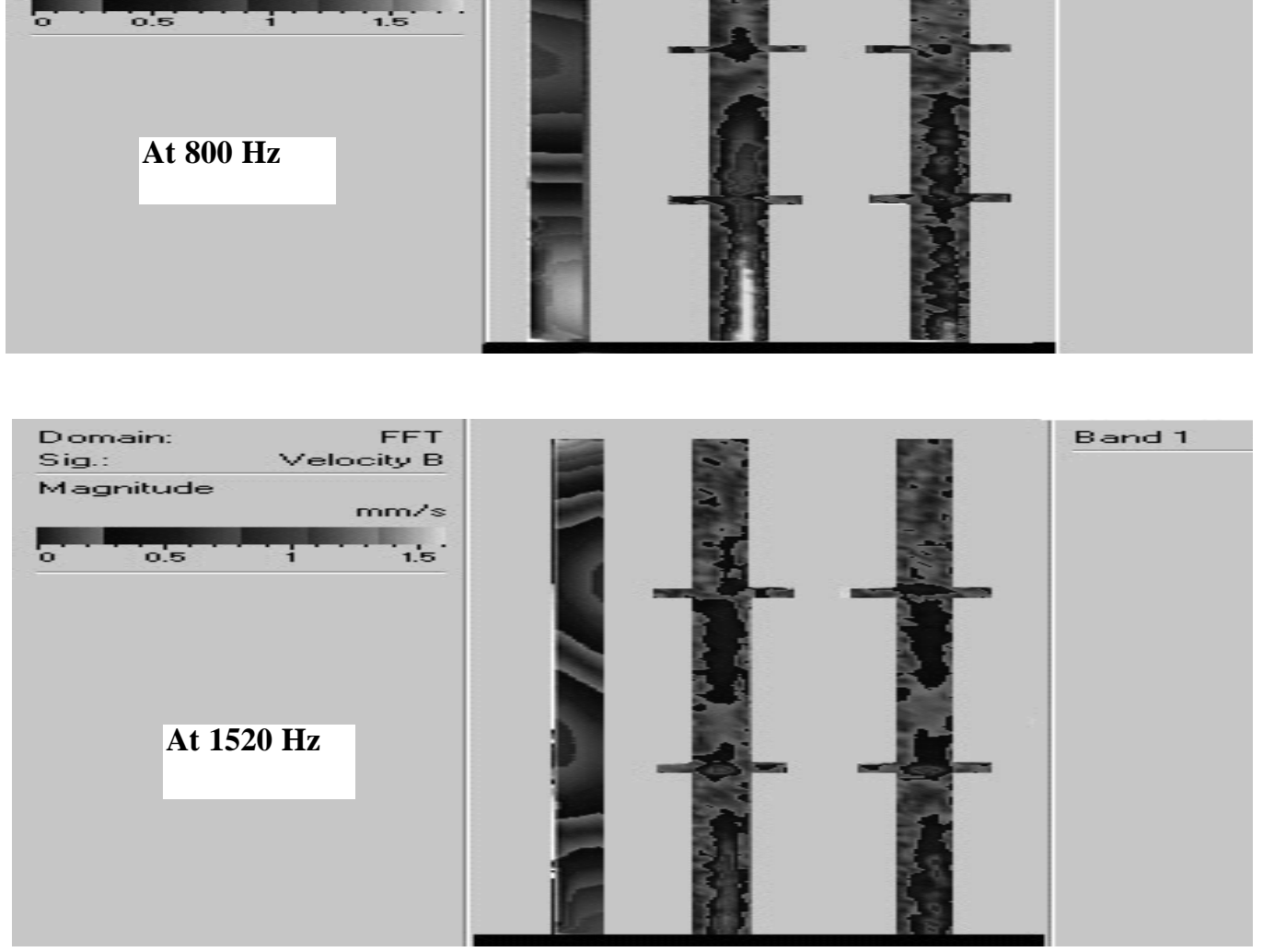

Figure 12. The vibration of plain, passive periodic and hybrid periodic rods at:
(a) $160 \mathrm{~Hz}$ (in pass band),
(b) $800 \mathrm{~Hz}$ (in stop band), and
(c) $1520 \mathrm{~Hz}$ (in stop band) 


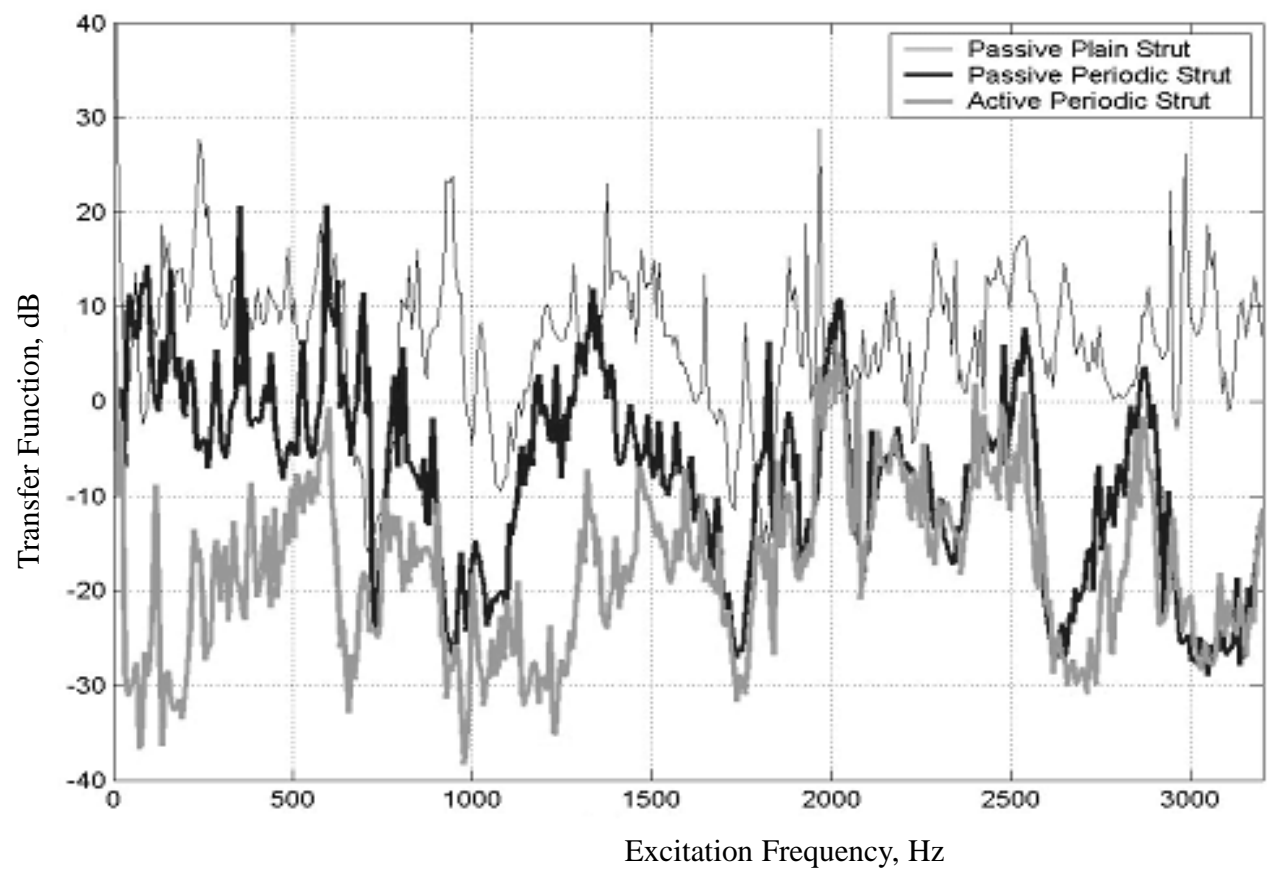

Figure 13. The transfer function in case of collocated sensor/actuator arrangement with broadband excitation from the motor

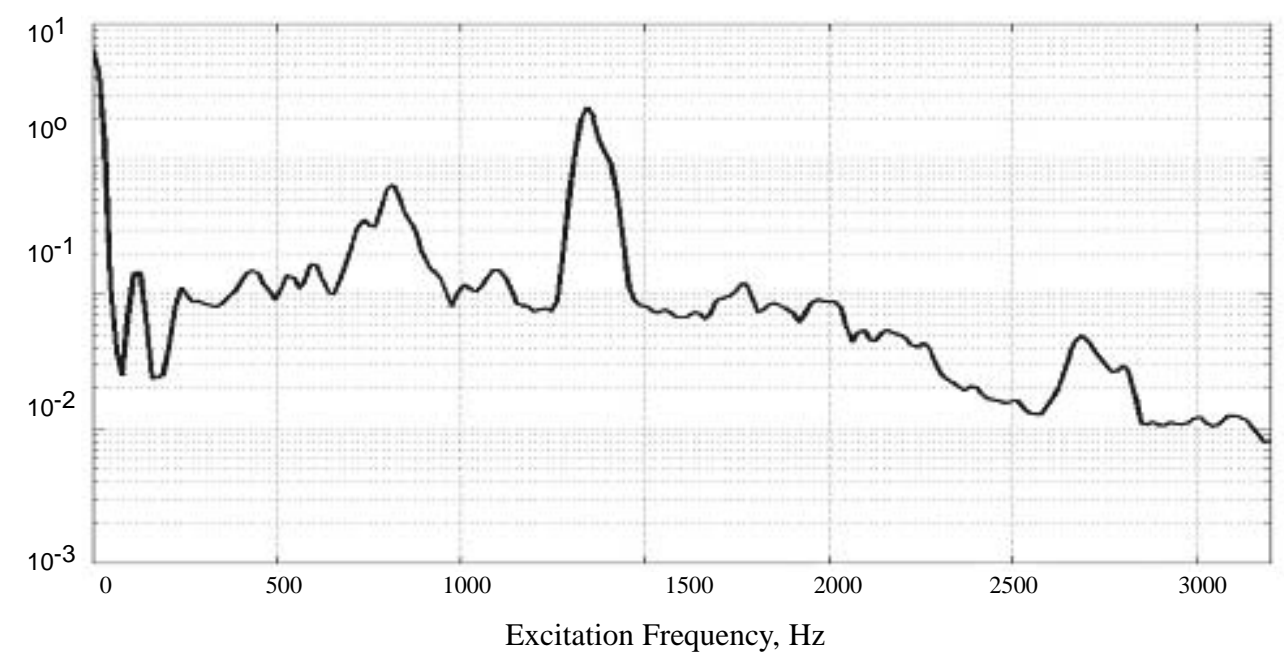

Figure 14. The control voltage applied to the upper control actuator

hybrid periodic rods installed between two plates. The theory governing the operation of this class of rods has been presented. The factors governing the design of effective periodic rods have been identified. The performance characteristics of passive and hybrid periodic rods alone have been measured experimentally and compared with the theoretical predictions of the real part of the propagation factor. Close agreement between theoretical predictions and experimental results has been achieved. The performance of the tunable mechanical filter with a motor assembly has also been monitored experimentally. The predictions of the stop bands have also been found to be in close agreement with the experimental results. The periodic rods in active mode are very efficient in the low frequency range while in the high frequency range they have the same efficiency of the passive mode. As a result, the mechanical filter with hybrid periodic rods is found to be more effective in attenuating the transmission of vibrations from the source of vibrations to the lower plate over a broader frequency range extending from 150-4000 Hz with control voltages not exceeding 5 volts.

This concept of the tunable mechanical filter can be implemented efficiently in many applications. For instant, the gearbox support system of helicopter and automotive vehicle engine mounting systems. With such unique filtering characteristics, it would be possible to control the wave propagation both in the spectral/spatial domains in an attempt to stop/confine the propagation of undesirable disturbances. 


\section{References}

Asiri, S., 2005, "Vibration Isolation of Automotive Vehicle Engine Using Periodic Mounting Systems," SPIE 2005, San Diego, California, USA.

Asiri, S., Baz, A. and Pines, D., 2004, "Active Periodic Struts for Gearbox support System," Proc. of SPIE, Smart Structures and Materials 2004: Damping and Isolation, Vol. 5386, pp. 347-358.

Asiri, S., Baz, A. and Pines, D., 2002, "Periodic Struts for Gearbox Support System," Proc. Of the 2002 International Congress and Exposition on Noise Control Engineering, Inter Noise 2002, Paper number IN02-644, Dearborn, MI, USA.

Baz, A., 2001, "Active Control of Periodic Structures," ASME Journal of Vibration and Acoustics, Vol. 123, pp. 472-479.

Baz, A., 2002, "Vibration Damping," Class Notes, University of Maryland at College Park.

Baz, A., 2000, "Spectral Finite Element Modeling of Longitudinal Wave Propagation in Rods with Active Constrained Layer Damping," Smart Materials and Structures, Vol. 9(3), pp. 372-377.

Brillouin, L., 1953, "Wave Propagation in Periodic Structures," 2nd ed. Dover.

Cremer, L., Heckel, M. and Ungar, E., 1973, "StructureBorne Sound," Springer-Verlag, New York.

Doyle, J., 1997, "Wave Propagation in Structures," 2nd ed., Springer-Verlag, New York.

Faulkner, M. and Hong, D., 1985, "Free Vibration of a Mono-Coupled Periodic System," J. of Sound and Vibrations, Vol. 99, pp. 29-42.

Gupta, S., 1970, "Natural Flexural Waves and the Normal Modes of Periodically-Supported Beams and Plates," J. of Sound and Vibration, Vol. 13, pp. 89-111.

Mead, D. J. , 1986, "A New Method of Analyzing Wave Propagation in Periodic Structures; Applications to Periodic Timoshenko Beams and Stiffened Plates," J. of Sound and Vibration, Vol. 114, pp. 9-27.

Mead, D.J., 1970, "Free Wave Propagation in Periodically Supported, Infinite Beams," J. of Sound and Vibration, Vol. 11, pp. 181-197.

Mead, D. J., 1971, "Vibration Response and Wave Propagation in Periodic Structures," J. of Engineering for Industry, Vol. 21, pp. 783-792.

Mead, D. J., 1975, "Wave Propagation and Natural Modes in Periodic Systems: I. Mono-Coupled Systems," J. of Sound and Vibration, Vol. 40, pp. 1-18.

Mead, D. J., 1996, "Wave Propagation in Continuous Periodic Structures: Research Contributions from Southampton," J. of Sound and Vibration, Vol. 190, pp. 495-524.

Mead, D. J. and Bardell, N. S., 1987, "Free Vibration of a Thin Cylindrical Shell with Periodic Circumferential Stiffeners," J. of Sound and Vibration, Vol. 115, pp. 499-521.

Mead, D. J. and Markus, S., 1983, "Coupled FlexuralLongitudinal Wave Motion in a Periodic Beam," J. of Sound and Vibration, Vol. 90, pp. 1-24.

Mead, D. J. and Yaman, Y., 1991, "The Harmonic Response of Rectangular Sandwich Plates with Multiple Stiffening: A Flexural Wave Analysis," J. of Sound and Vibration, Vol. 145, pp. 409-428.

Orris, R. and Petyt, M., 1974, "A Finite Element Study of Harmonic Wave Propagation in Periodic Structures," J. of Sound and Vibration, Vol. 33(2), pp. 223-237.

Patera, A., 1984, "A Spectral Element Method for Fluid Dynamics: Laminar Flow in Channel Expansion," J. of Comput. Physics, Vol. 54, pp. 468-488.

Pierre, C., 1988, "Mode Localization and Eigenvalue Loci Veering Phenomena in Disordered Structures," J. of Sound and Vibration, Vol. 126, pp. 485-502.

Ravindra, B. and Mallik, K., 1992, "Harmonic Vibration Isolation Characteristics of Periodic Systems," J. of Sound and Vibration, Vol. 154(2), pp. 249-259.

Richards, D. and Pines, D.J., 2003, "Passive Reduction of Gear Mesh Vibration Using a Periodic Drive Shaft," J. of Sound and Vibration, Vol. 264(2), pp. 317-342.

Roy, A. and Plunkett, R., 1986, "Wave Attenuation in Periodic Structures," J. of Sound and Vibration, Vol. 114, pp. 395-411.

Ruzzene, G. and Baz, A., 2000, "Control of Wave Propagation in Periodic Composite Rods using Shape Memory Inserts," J. of Vibration and Acoustics, Vol. 122, pp. 151-159.

Sackman, S., Kelly, J. and Javid, A. A., 1999, "Layered Notch Filter for High-Frequency Dynamic Isolation," J. of Pressure Vessel Technology, Vol. 111, pp. 17-24.

Singh, A., Pines, D. and Baz, A., 2004, "Active/Passive Reduction of Vibration of Periodic One-Dimensional Structures using Piezoelectric Actuators," Smart Materials and Structures, Vol. 13, pp. 698-711.

Snowden, J.C., 1979, "Vibration Isolation: Use and Characterization," NBS Handbook, Vol. 128, US National Bureau of Standards.

Szefi, J., Smith, E. and Lesieutre, G., 2004, "Design and Testing of a Compact Layered Isolator for HighFrequency Helicopter Gearbox Isolation," Prec. Of 45th AIAA Structures, Structural Dynamics and Materials Conference, Palm Spring, CA, USA. 